\title{
Application of NMR Relaxometry to Study Nanostructured Poly(vinyl alcohol)/MMT/ Cephalexin Materials for Use in Drug Delivery Systems
}

\author{
Antonio de Pádua Castelo Branco Cunha, Maria Inês Bruno Tavares, \\ Emerson Oliveira da Silva \\ Instituto de Macromoléculas Professora Eloisa Mano da Universidade Federal do Rio de Janeiro, CT, Bloco J, \\ Cidade Universitária, Ilha do Fundão, Rio de Janeiro, Brazil \\ Email:mibt@ima.ufrj.br
}

Received 19 June 2016; accepted 24 July 2016; published 27 July 2016

Copyright (C) 2016 by authors and Scientific Research Publishing Inc. This work is licensed under the Creative Commons Attribution International License (CC BY). http://creativecommons.org/licenses/by/4.0/

cc) (i) Open Access

\begin{abstract}
Polymers containing nanoparticles dispersed and distributed in the matrix can be used for control of drug release. In this work, hydrophilic matrix systems were prepared using poly(vinyl alcohol) and unmodified clay containing the same amount of cephalexin. The materials were obtained through in situ polymerization and were characterized by the conventional technique of FTIR and NMR relaxometry, through determination of proton spin-lattice relaxation time, in order to understand the molecular behavior of the new materials. The NMR relaxometry data showed that the new materials containing low quantities of clay $(0.25 \%$ and $0.75 \%)$ and the same amount of cephalexin ( $0.5 \mathrm{~g})$ had very good dispersion and distribution of the clay and drug in the polymer matrix. The combination of clay and cephalexin formed a more homogenous material with a narrow domain curve and low relaxation values. The material containing $0.25 \%$ clay presented a mixed morphology, with part exfoliated and part intercalated, as could be seen from the relaxation domain distribution, which was larger than that for material with $0.75 \%$ clay.
\end{abstract}

\section{Keywords}

Polymer, Relaxometry, NMR, Nanotechnology

\section{Introduction}

The generation of nanostructured systems for application in the pharmaceutical industry has been a subject of 
many studies around the world, particularly to develop drug delivery systems [1]-[3].

Many types of matrices are used in drug delivery systems. If the polymer matrix is insoluble, an inert matrix will be formed, with a porous structure, from where the drug can be dispersed, but the material needs to have the same apparent surface area during the dissolution and diffusion to control these factors [1]. Therefore, the properties of hydrophobic matrices will depend on both the drug and excipient used for determination of the release mechanism, which can occur by erosion or diffusion through the pores. However, if the matrix formulation contains a hydrophilic polymer, it can provide an appropriate combination of swelling dissolution or erosion mechanisms. The predominance of one of these mechanisms invariably depends on the properties of the polymer used in the system, among which poly(vinyl alcohol) (PVAL) stands out. In this work we prepared a hydrophilic nanostructured system using poly(vinyl alcohol), because this polymer had very good characteristics for use as a hydrophilic matrix for delivery of hydrophilic drugs like cephalexin.

Poly(vinyl alcohol) is a water-soluble synthetic polymer that is used in papermakers, textiles, and a variety of coatings. It is resistant to oil, grease and solvents. It also has high tensile strength and flexibility, as well as high oxygen and aroma barrier properties. However, these properties are dependent on humidity. In other words, with higher humidity more water is absorbed. The water, which acts as a plasticizer, then reduces the material's tensile strength, but increases its elongation and tear strength. PVA has a melting point of $230^{\circ} \mathrm{C}$ [4].

Cefalexin is a semi synthetic cephalosporin antibiotic for oral administration. It is indicated for the treatment of respiratory tract infections; otitis media; skin and soft tissue infections; bone and joint infections; genito-urinary infections, including acute prostatitis; and dental infections. Cefalexin is active against the following organisms in vitro: $\beta$-haemolytic streptococci; staphylococci, including coagulase-positive, coagulase-negative and penicillinase-producing strains; Streptococcus pneumoniae; Escherichia coli; Proteus mirabilis; Klebsiella species; Haemophilus influenzae; and Branhamella catarrhalis. Most strains of enterococci (Streptococcus faecalis) and a few strains of staphylococci are resistant to cefalexin. The drug is inactive against most strains of enterobacteria, morganella morganii, pr. Vulgaris, Colstridium difficule, and the following species: legionella, campylobacter, pseudomonas or herellea species. When tested by in vitro methods, staphylococci exhibit cross-resistance between cefalexin and methicillin-type antibiotics [5].

The main objective of this work was to prepare hydrophilic matrix systems using poly(vinyl alcohol) and unmodified clay and cephalexin. The second objective was to evaluate the interaction among the components and the dispersion and distribution of clay and cephalexin in the polymer matrix, focusing on the characterization of the new materials, especially from nuclear magnetic resonance (NMR) relaxometry.

NMR relaxometry is chosen because it involves measurement of proton relaxation times, which are sensitive to changes in molecular mobility. As a consequence, proton spin-lattice relaxation time indicates the morphologies of the material, such as intercalated and exfoliated structures in the case of clay nanoparticles [6]-[10]. Generally speaking, the decrease in the proton spin-lattice relaxation time comes from the clay lamellae's exfoliation because the presence of paramagnetic metals in the presence of clay structure interferes in the near proton relaxation mechanism. The contrary effect in proton relaxation time is expected for the samples containing polymer chains intercalated in the clay lamellae because of the restriction of their molecular mobility [7]-[12].

\section{Experimental}

\subsection{Sample Preparation}

The PVAL/clay nanocomposites were prepared by in situ polymerization, with varied clay content $(0.25 \%$, $0.75 \%, 1.0 \%, 1.5 \%$ and $3.0 \%$ ). The drug was also added in the in situ polymerization. The PVAL/clay/cephalexin nanocomposites containing the five different amounts of clay and with the same cephalexin content were obtained.

\subsection{FTIR Measurements}

The infrared spectra of the nanomaterial films were recorded with a Varian Excalibur 3100 FTIR spectrometer with Pike Technologies MIRacle ATR accessory, with 100 scans, resolution of $4 \mathrm{~cm}^{-1}$, from 400 to $4000 \mathrm{~cm}^{-1}$ wavelength.

\subsection{NMR Relaxometry}

All NMR relaxation measurements were carried out with a Maran Ultra 23 Spectrometer (Oxford Instruments, 
UK), operating at $23 \mathrm{MHz}$ (for protons) and equipped with an $18 \mathrm{Nm}$ NMR tube. Proton spin- lattice relaxation times with a time constant $\left(\mathrm{T}_{1} \mathrm{H}\right)$ were determined by inversion-recovery (recycle delay- $180^{\circ}-\tau$ - $90^{\circ}$ acquisition data) pulse sequence. The temperature was $27^{\circ} \mathrm{C}$ and the range of $\tau$ varied from 0.1 to $10.000 \mathrm{~ms}$, with a recycle delay of $5 \mathrm{~s}$. The $90^{\circ}$ pulse was automatically calibrated and the relaxation values were obtained by fitting with WINFIT, while the domain distribution was obtained by the WINDXP software, which comes with the spectrometer.

\section{Results and Discussion}

\subsection{FTIR Analysis}

Figure 1 shows the structure of cephalexin. The major absorption bands in the FITR cephalexin spectrum are observed at about $3500 \mathrm{~cm}^{-1}$, attributed to the hydroxyl groups; $3000 \mathrm{~cm}^{-1}$, related to the methyl group, and an intense band between $1800-1700 \mathrm{~cm}^{-1}$, corresponding to the carbonyl group from the beta lactam ring.

Figures 2-6 show the FTIR spectra of the PVAL/Clay/cephalexin systems containing different amount of clay, but the same amount of cephalexin. These samples present characteristics of both PVAL and cephalexin compounds, the peak located at $3420 \mathrm{~cm}^{-1}$ is associated with the hydroxyl group of PVAL. The presence of wide

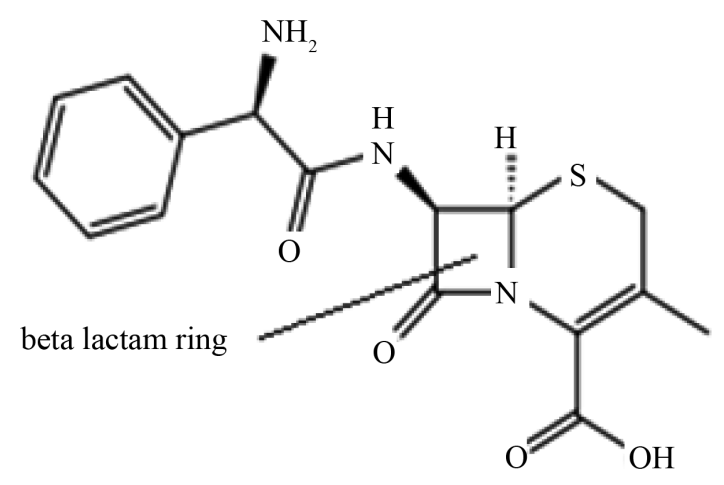

Figure 1. Structure of cephalexin.

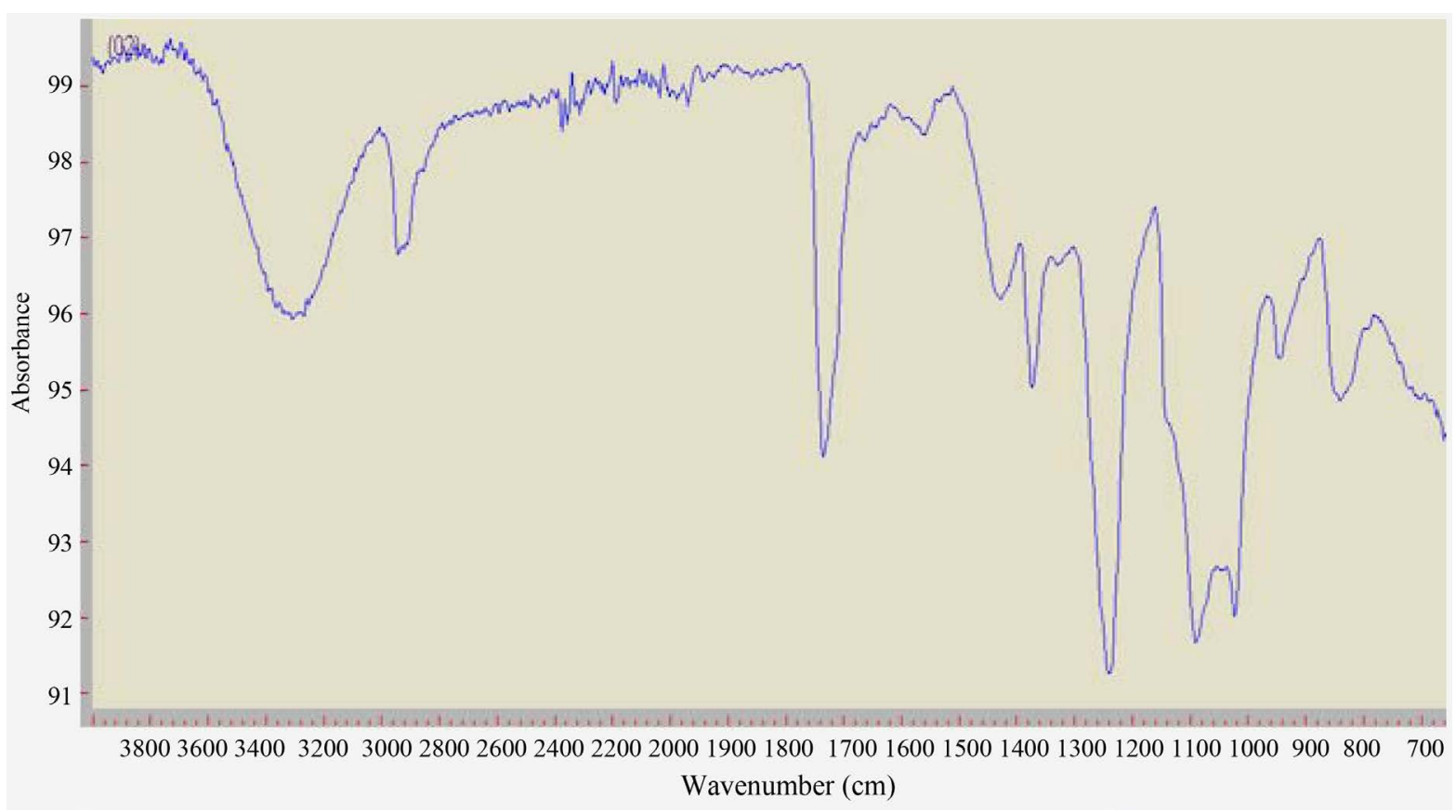

Figure 2. FTIR spectrum of the system formed by PVAL/Clay/cephalexin containing $0.25 \%$ clay and $0.5 \mathrm{~g}$ of cephalexin. 


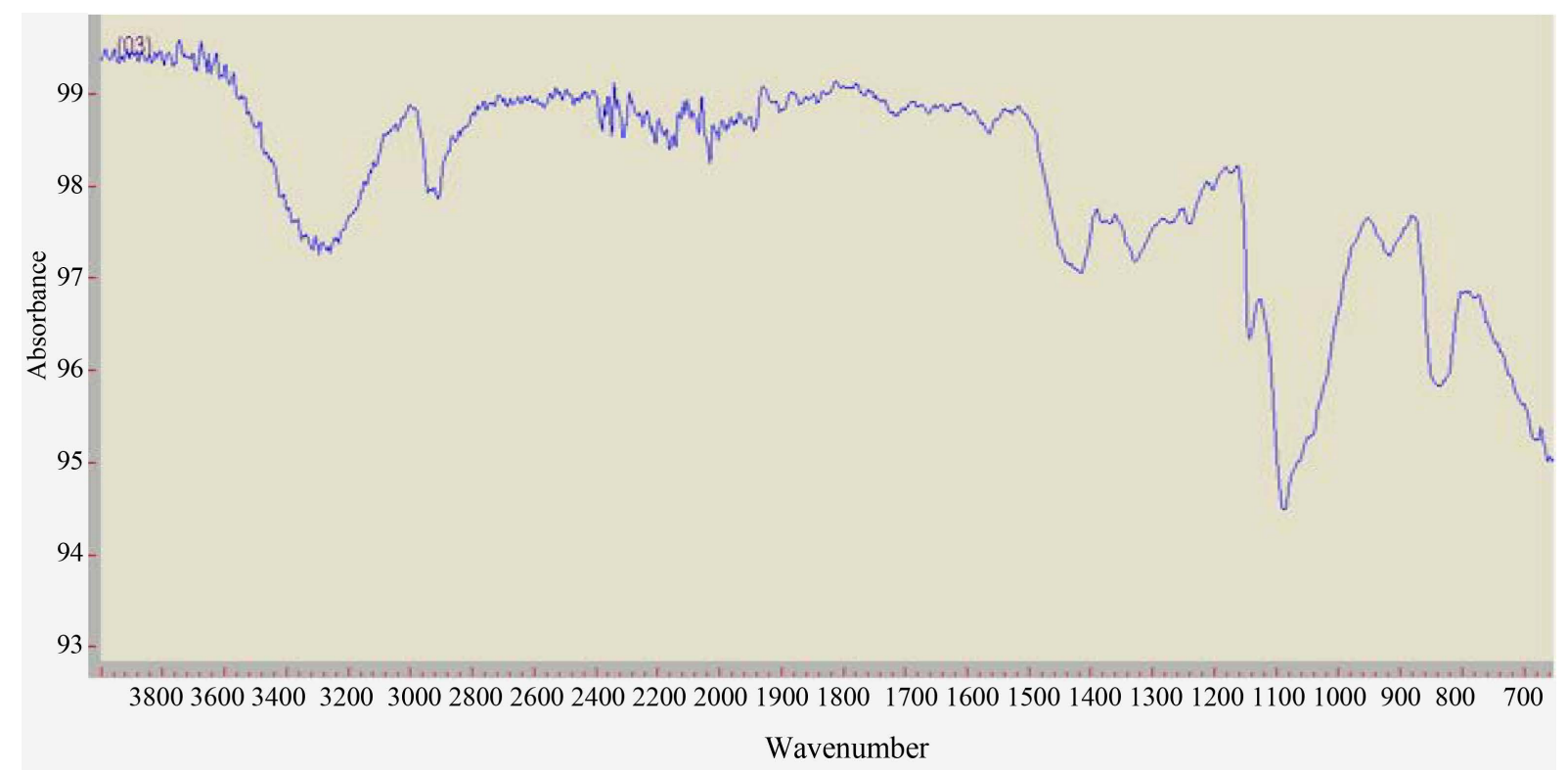

Figure 3. FTIR spectrum of the system formed by PVAL/Clay/cephalexin containing $0.75 \%$ clay and $0.5 \mathrm{~g}$ of cephalexin.

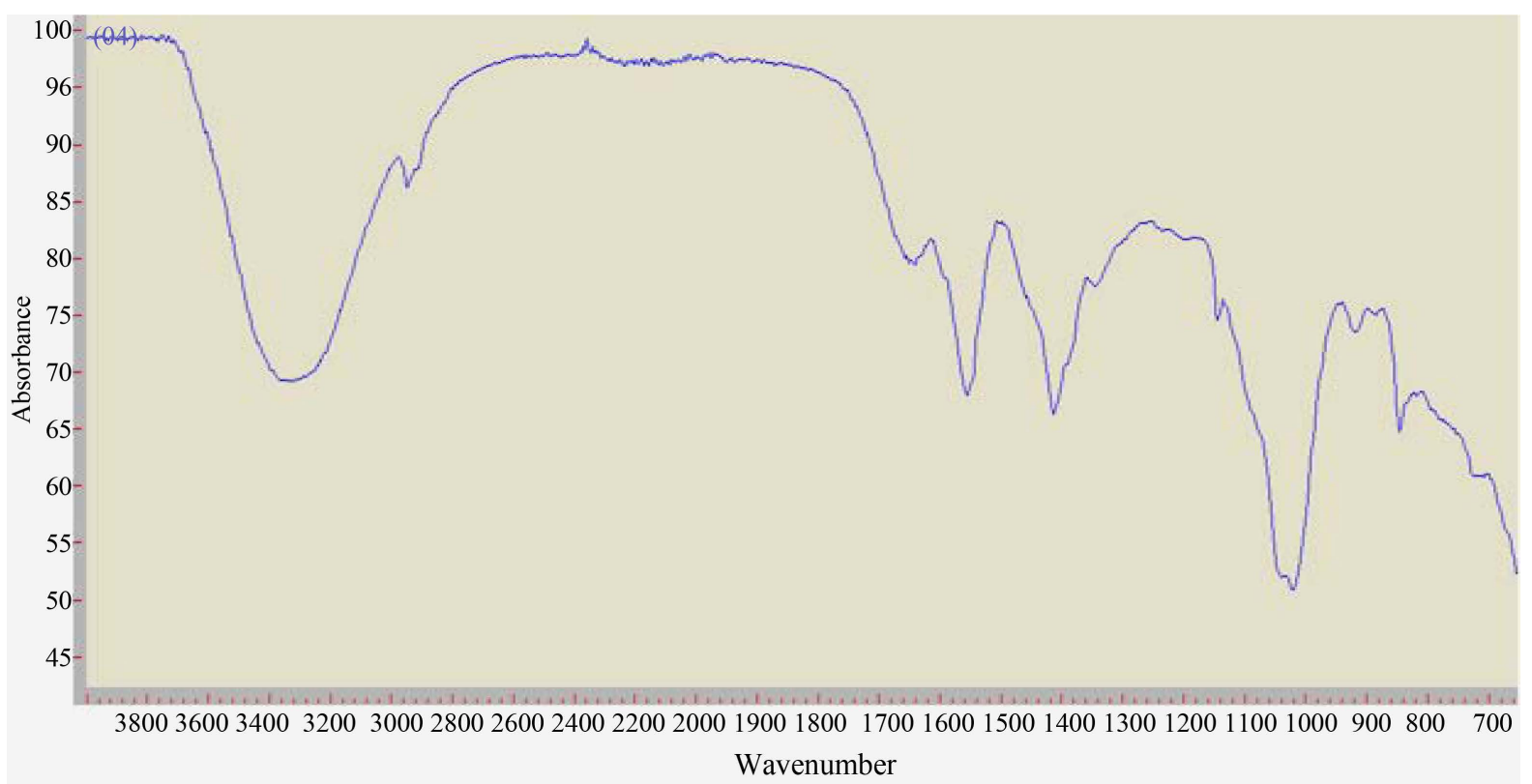

Figura 4. FTIR spectrum of the system formed by PVAL/Clay/cephalexin containing $1.0 \%$ clay and $0.5 \mathrm{~g}$ of cephalexin.

bands corresponding to axial deformation of $\mathrm{OH}$ (alcohol) located in the range of $3550-3200 \mathrm{~cm}^{-1}$ indicates the presence of hydrogen bonding, while the absence of strong absorption in the $3650-3584 \mathrm{~cm}^{-1}$ range is characteristic of free $\mathrm{OH}$ indicates a high concentration of intermolecular linked hydroxyl. The absorption with broad band between $3300-2500 \mathrm{~cm}^{-1}$, characteristic of axial deformation of $\mathrm{OH}$ free carboxylic acid (cephalexin), is present in the spectra. We also noted absence of an aliphatic C=O absorption band between $1750-1753 \mathrm{~cm}^{-1}$. The interpretation of the spectra indicates there was negligible interaction between the polymer matrix and drug (cephalexin).

\subsection{NMR Relaxometry Measurements}

Table 1 shows the proton spin-lattice relaxation data of the PVAL/Clay/cephalexin systems. It can be seen that 


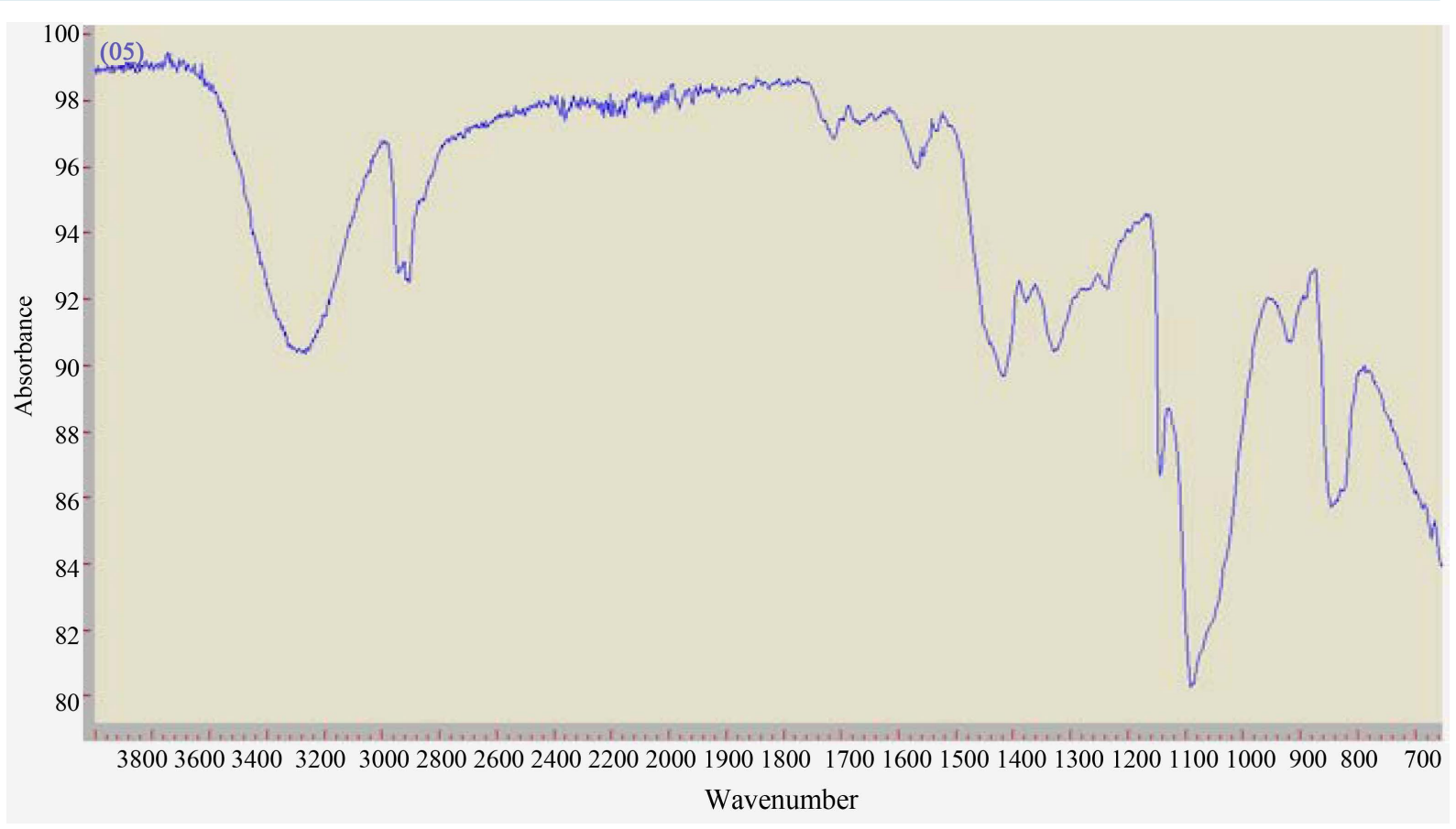

Figure 5. FTIR spectrum of the system formed by PVAL/Clay/cephalexin containing $1.5 \%$ clay and $0.5 \mathrm{~g}$ of cephalexin.

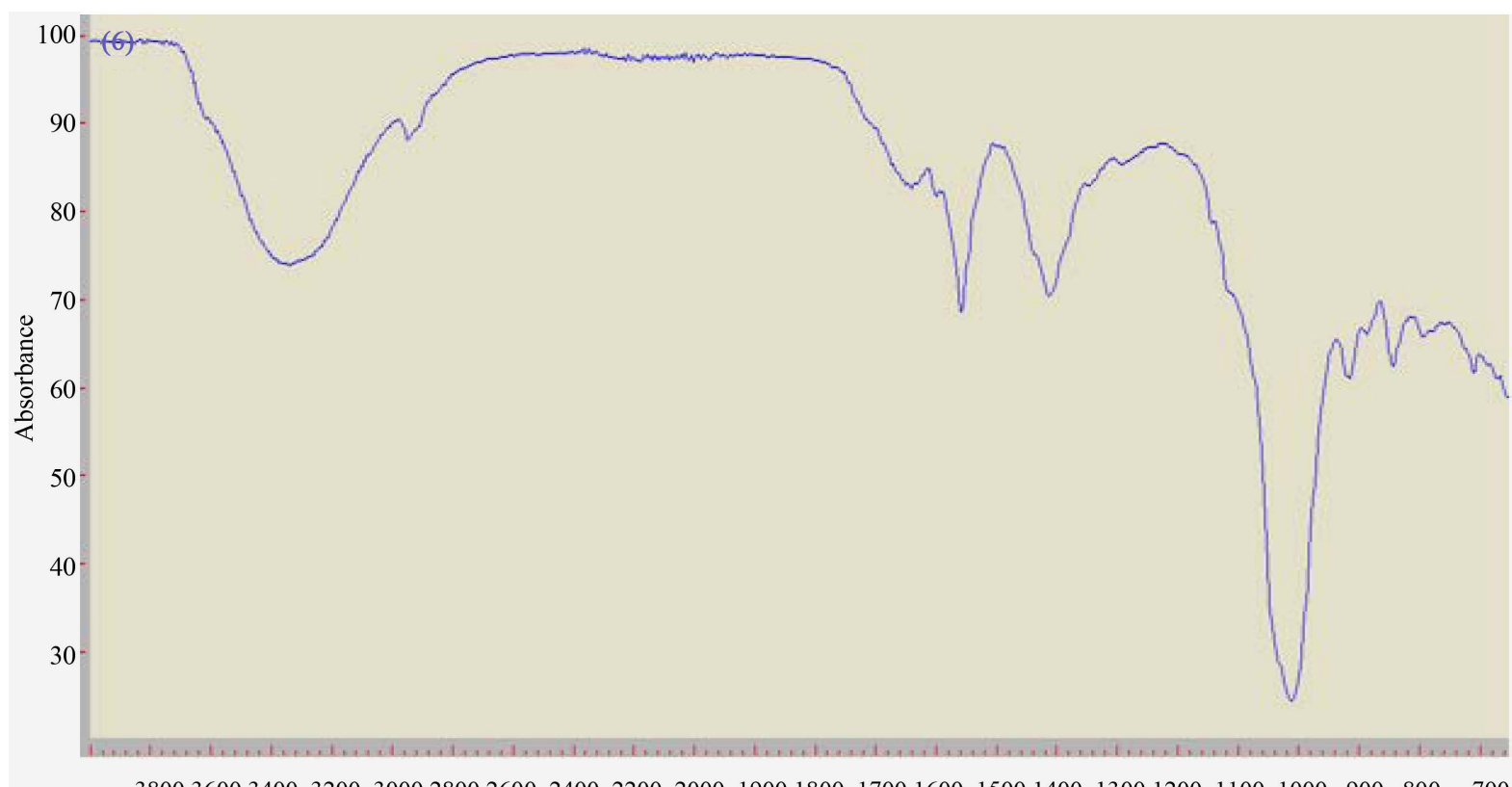

Wavenumber

Figure 6. FTIR spectrum of the system formed by PVAL/Clay/cephalexin containing $3.0 \%$ clay and $0.5 \mathrm{~g}$ of cephalexin.

the increase clay concentration from $0.25 \%$ to $3.0 \%$ caused the samples to present particular behavior. The proton relaxation times decreased very quickly with the addition of only $0.25 \%$, revealing formation of a mixed nanostructured material containing part exfoliated and part intercalated. The addition of $0.75 \%$ caused greater decrease in the relaxation time, derived from the increase in the exfoliated part in the new material. This behavior comes from the more exfoliated domain, which causes an increase in the chains' molecular mobility, since they are free to move around between the clay lamellae. As the amount of clay increased, the relaxation time 
Table 1. $\mathrm{T}_{1} \mathrm{H}$ values for the PVAL/Clay/cephalexin systems.

\begin{tabular}{cc}
\hline PVAL/Clay/Cephalexin Systems & $\mathbf{T}_{\mathbf{1}} \mathbf{H}(\mathbf{m s}) \pm \mathbf{2 \%}$ \\
\hline PVAL & 247 \\
PVAL/0.25/0.5g & $\mathbf{1 1 0} \downarrow$ \\
PVAL/0.75/0.5g & $\mathbf{9 3} \downarrow$ \\
PVAL/1.0/0.5g & 96 \\
PVAL/1.5/0.5g & 95 \\
PVAL/3.0/0.5g & 96 \\
\hline
\end{tabular}

showed a tendency to remain the same or increase slightly. The results revealed that all samples presented good exfoliation. Therefore, the addition of only $0.25 \%$ clay caused a dramatic change in the relaxation parameter, while a small increase in the quantity to $0.75 \%$ caused another decrease in this parameter, showing that both systems underwent changes in the PVAL/Clay/cephalexin chains' molecular mobility, because of the better dispersion and distribution of clay in the polymer matrix. Therefore, addition of $0.25 \%$ clay promoted a substantial change in the PVAL/Clay/cephalexin organization, while addition of $0.75 \%$ clay generated materials with higher proportion of exfoliation. The decrease in the relaxation times is related to the freedom of movement of the chains between clay lamellae, and only exfoliation of clay makes this possible. This behavior has already been seen for other systems [6]-[10] corroborating the data obtained for the system analyzed here.

We also can say that the relaxation time data support the behavior observed in the Fourier-transform infrared spectra.

The domain curve distribution of relaxation parameters determined for the PVAL/Clay/cephalexin systems are seen in Figure 7. From the behavior of these curves, we can obtain information on the samples' homogeneity.

In Figure 7, the polymer itself showed a narrow domain distribution curve, which is in accordance with the chains' organization, since its molecular organization is high. As the clay and drug were added in the polymerization process, the new materials presented different molecular organization due to the new intermolecular interactions. The addition of 0.25 clay caused a large change in the molecular organization due to the wideness of the domain curve baseline; this amount of clay caused some heterogeneity in the polymer nanostructure organization, probably due to the formation of a mixture of systems containing part exfoliated and part intercalated in the clay structures. The addition of $0.75 \%$ clay produced a narrower domain curve than with $0.25 \%$ clay, indicating that in this proportion a more homogenous domain was formed, probably a major quantity of exfoliated clay lamellae occurred. With the addition of $1.0 \%$ and $1.5 \%$ clay, the domain curves show the same behavior and are wider than with $0.75 \%$ clay added, suggesting a more heterogeneous mix of systems was formed. With addition of $3 \%$ clay an even more heterogeneous system was formed than with $1 \%$ and $1.5 \%$. The behavior of domain curves distribution corroborates with the relaxation time results.

Figure 8 shows the behavior of the proton spin-lattice relaxation time with increasing clay content. There was a deep decrease in the value of relaxation time for the smallest amount of clay $(0.25 \%)$, followed by another decrease after the addition of $0.75 \%$, after which the values remained the same with increase of clay content up to $3 \%$. This behavior shows that there is a dependence with relaxation data and clay proportion up to $0.75 \%$ of clay addition, for the others quantity no influence in this parameter was observed.

The MNR relaxometry was very effective in analyzing the PVAL/Clay/cephalexin systems; making it a good alternative technique to evaluate polymer/nanoparticles systems, since it allows observing the sample in various modes and the results obtained can explain the molecular dynamics of the sample and indicate the organization mode. This technique can also support the data obtained from other techniques commonly used to evaluate nanomaterials, and therefore gives a good response regarding dispersion and distribution of nanoparticles.

\section{Conclusions}

A series of nanocomposite materials composed of layers of montmorillonite (MMT) clay can be prepared by dispersion in PVAL, via in situ polymerization of vinyl acetate monomer, followed by hydrolysis with $\mathrm{NaOH}$ solution. The system investigated shows a marked degree of exfoliation, which demonstrates the possibility of controlling drug delivery by varying the clay content, since the insertion alters the degree of crystallinity of 


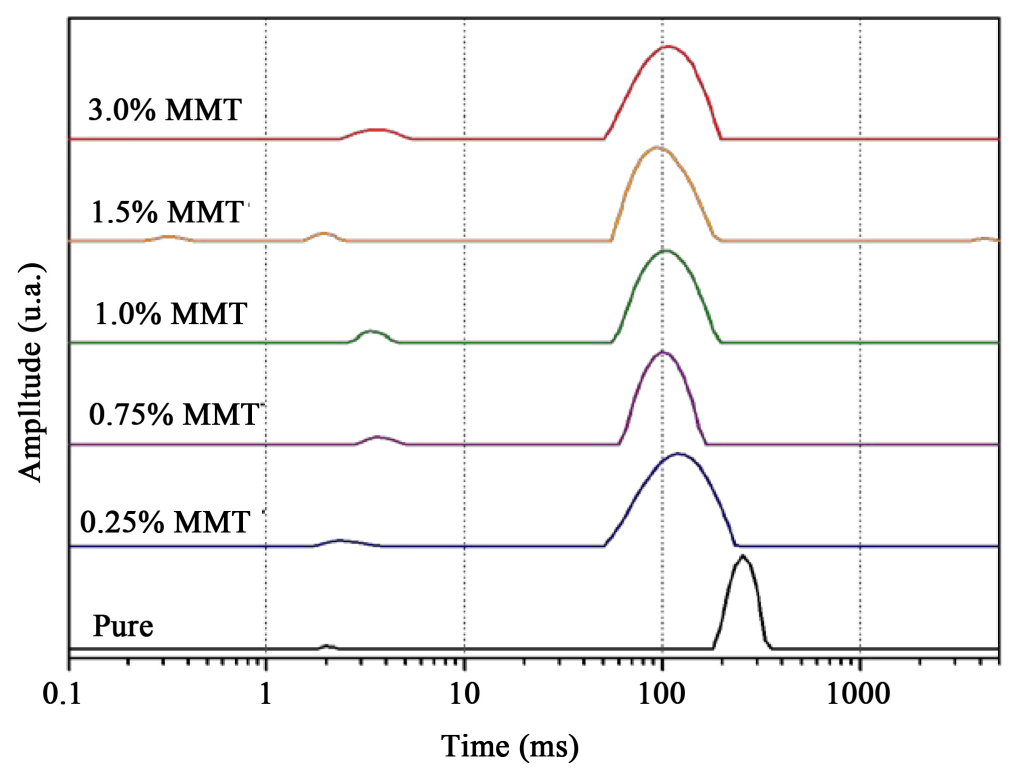

Figure $7 . \mathrm{T}_{1} \mathrm{H}$ relaxation domain curves.

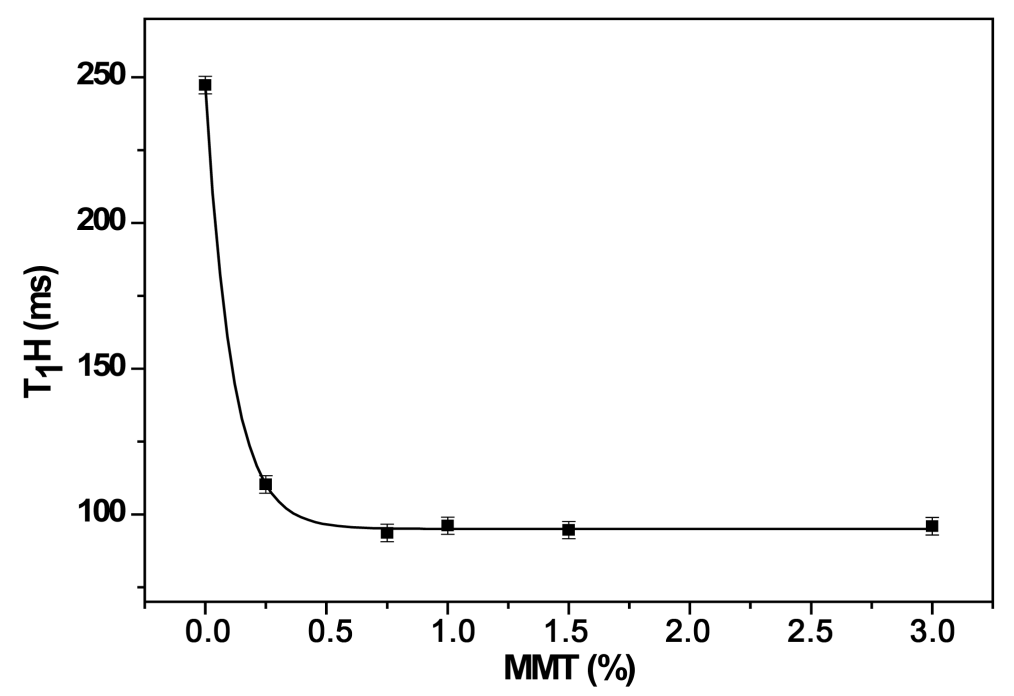

Figure 8 . The behavior of $\mathrm{T}_{1} \mathrm{H}$ values versus clay quantity.

PVAL, while there is little interaction of the drug with the polymer matrix, meaning it is possible to modulate the rate of delivery according to the structural arrangement.

The relaxation measurements provide relevant information-a profound structural modification in the polymer matrix is observed for the samples containing $0.25 \%$ clay in PVAL.

\section{Acknowledgements}

We are grateful to CAPES, CNPq and FAPERJ for supporting this study.

\section{References}

[1] Ansel, H.C., Popovich, N.G. and Allen, L.V. (2007) Formas farmacêuticas com velocidade controlada e sistemas de liberação de fármacos. In: Farmacotécnica: formas farmacêuticas e sistemas de liberação de fármacos, Chapter 9, Premier, São Paulo, 283-300.

[2] Chan, J.M., Valencia, P.M., Zang, L., Langer, R. and Farokhzad, O.C. (2010) Polymeric Nanoparticles for Drug Deli- 
very. Methods in Molecular Biology, 624, 163-175.

[3] Kawashima, Y. (2001) Nanoparticulate Systems for Improved Drug Delivery. Advanced Drug Delivery Reviews, 47, 1-2. http://dx.doi.org/10.1016/S0169-409X(00)00117-4

[4] Filho, J.C.D. and Gomes, A.S. (2011) Hybrid Membranes of PVA for Direct Ethanol Fuel Cells (DEFCs) Applications. International Journal of Hydrogen Energy, 37, 6246-6252.

[5] Molokhia, A.M. (1984) Res Commun Chem Pathol Pharmacol, 45, 219-224.

[6] dos Santos Almeida, A., Tavares, M.I.B., de Silva, E.O., Cucinelli Neto, R.P. and Moreira, L.A. (2012) Development of Hybrid Nanocomposites Based on PLLA and Low-Field NMR Characterization. Polymer Testing, 31, 267-275. http://dx.doi.org/10.1016/j.polymertesting.2011.11.005

[7] Brito, L.M., Chávez, F.V., Tavares, M.I.B. and Sebastião, P.J.O. (2013) Molecular Dynamic Evaluation of Starch-PLA Blends Nanocomposite with Organoclay by Proton NMR Relaxometry. Polymer Testing, 32, 1181-1185. http://dx.doi.org/10.1016/j.polymertesting.2013.07.002

[8] Monteiro, M.S.S.B., Chávez, F.V., Sebastião, P.J. and Tavares, M.I.B. (2013) 1H NMR Relaxometry and X-Ray Study of PCL/Nevirapine Hybrids. Polymer Testing, 32, 553-566. http://dx.doi.org/10.1016/j.polymertesting.2013.01.016

[9] Brito, L.M. and Tavares, M.I.B. (2012) Evaluation of the Influence of Nanoparticles' Shapes on the Formation of Poly(lactic acid) Nanocomposites Obtained Employing the Solution Method. Journal of Nanoscience and Nanotechnology, 12, 4508-4513.

[10] Vanderhart, D.L., Asano, A. and Gilman, J.W. (2001) Solid-State NMR Investigation of Paramagnetic Nylon-6 Clay Nanocomposites. 1. Crystallinity, Morphology, and the Direct Influence of $\mathrm{Fe}^{3+}$ on Nuclear Spins. Chemistry of Materials, 13, 3781-3795. http://dx.doi.org/10.1021/cm0110775

[11] Cunha, A.P.C.B., Tavares, M.I.B., Silva, E.O. and Zaioncz, S.J. (2015) The Effect of Montmorillonite Clay on the Crystallinity of Poly(vinyl alcohol) Nanocomposites Obtained by Solution Intercalation and in Situ Polymerization. Journal of Nanoscience and Nanotechnology, 15, 2814-2820

[12] Iulianelli, G.C.V., Sebastião, P.J.O., Tavares, M.I.B. and dos Santos, F.A. (2015) Influence of Organoclay Structure on Nanostructured Materials Based on Eva. Materials Sciences and Applications, 6, 860-868. http://dx.doi.org/10.4236/msa.2015.610088

\section{Submit or recommend next manuscript to SCIRP and we will provide best service for you:}

Accepting pre-submission inquiries through Email, Facebook, LinkedIn, Twitter, etc. A wide selection of journals (inclusive of 9 subjects, more than 200 journals)

Providing 24-hour high-quality service

User-friendly online submission system

Fair and swift peer-review system

Efficient typesetting and proofreading procedure

Display of the result of downloads and visits, as well as the number of cited articles

Maximum dissemination of your research work

Submit your manuscript at: http://papersubmission.scirp.org/ 